\title{
Le Parnasse du théâtre. Les recueils d'CEuvres complètes de théâtre au XVII siècle, Georges Forestier, Edric Caldicott et Claude Bourqui (dir.)
}

\section{Monica Pavesio}

\author{
(2) OpenEdition \\ Journals \\ Edizione digitale \\ URL: http://journals.openedition.org/studifrancesi/7199 \\ DOI: $10.4000 /$ studifrancesi.7199 \\ ISSN: 2421-5856 \\ Editore \\ Rosenberg \& Sellier \\ Edizione cartacea \\ Data di pubblicazione: 1 avril 2010 \\ Paginazione: 139-140 \\ ISSN: 0039-2944

\section{Notizia bibliografica digitale} \\ Monica Pavesio, «Le Parnasse du théâtre. Les recueils d'Euvres complètes de théâtre au xvII siècle, \\ Georges Forestier, Edric Caldicott et Claude Bourqui (dir.)», Studi Francesi [Online], 160 (LIV | I) | 2010, \\ online dal 30 novembre 2015, consultato il 13 janvier 2021. URL: http://journals.openedition.org/ \\ studifrancesi/7199 ; DOI: https://doi.org/10.4000/studifrancesi.7199
}

Questo documento è stato generato automaticamente il 13 janvier 2021.

\section{c)}

Studi Francesi è distribuita con Licenza Creative Commons Attribuzione - Non commerciale - Non opere derivate 4.0 Internazionale. 


\title{
Le Parnasse du théâtre. Les recueils
} d'Cuvres complètes de théâtre au XVII siècle, Georges Forestier, Edric Caldicott et Claude Bourqui (dir.)

\author{
Monica Pavesio
}

\section{NOTIZIA}

Le Parnasse du théâtre. Les recueils d'CEuvres complètes de théâtre au XVII' siècle, Georges FORESTIER, Edric CALDICOTT et Claude BOURQUI (dir.), Paris, PUPS, 2007, pp. 350.

1 Nella seconda metà del xvII secolo assistiamo alla pubblicazione di numerose edizioni complete delle opere degli autori di teatro. Il fenomeno, già presente, in forma minore, nella prima metà del secolo, si intensifica e si estende ai drammaturghi direttamente collegati alle produzioni teatrali, ossia agli autori comici come Molière, le cui opere vengono pubblicate nel 1682 in una monumentale edizione. Queste edizioni, che sembrano riconoscere ai drammaturghi uno stato equivalente a quello degli scrittori dei generi nobili, danno origine a quello che i tre curatori del volume chiamano Parnasse des auteurs dramatiques.

2 Il volume, introdotto da $\mathrm{Cl}$. Bourqui, riunisce i quattordici contributi presentati in occasione del convegno organizzato dal Centre de Recherche sur l'Histoire du Théâtre dell'Università di Paris-Sorbonne diretto da G. Forestier nel 2005. Noi ci limiteremo a segnalare i contributi relativi alla Francia o a drammaturghi francesi.

3 Nella seconda sezione dal titolo «Imprimer le texte de théâtre», i contributi L'aventure éditoriale du théâtre imprimé entre 1630 et 1660 di A. RIFFAUD; Editer Molière aux Pays-Bas au XVII siècle di P.J.SMITH; Les partitions théâtrales au XVII siècle: des débuts jusqu'au Malade imaginaire di J.S. POWELL. 
4 Nella terza sezione, «Imprimer les ornements», il saggio Les stratégies éditoriales et les "letture sceniche" de Giovan Battista Andreini, comico dell'arte di L. MARITI, che si sofferma soprattutto sulla pubblicazione delle opere del comico in Francia; Les éditions illustrées d'Euvres dramatiques groupées ou composites, publiées en France dans la première moitié du XVII siècle di C. GUILLOT; La présence de la musique dans les recueils d'œuvres complètes de théâtre du XVII siècle di A.M. GOULET.

5 Nella quarta sezione, «Des précurseurs aux stratégies individuelles», i lavori di D. MONCOND'HuY, Des Cuvres complètes et de la pratique du recueil composite au Théâtre complet, de Theophile de Viau à Corneille: l'émergence de la figure du dramaturge en autorité; di A. HOWE, L'entrée au Parnasse d'un dramaturge professionnel: le cas d'Alexandre Hardy; di W. KIRSOP, Rotrou: l'exception qui confirme la règle?; di G. FORESTIER, Racine et ses publications: de l'actualité des pièces au monument des Euvres; di Eric CALDICOTT, Les stemmata et le privilège de l'édition des Euvres complètes de Molière (1682); di B. Louvat-molozay, Les Euvres complètes des comédiens-auteurs. Les exemples de Poisson et de Montfleury; di P. GETHNER, Stratégies de publication et notions de carrière chez les femmes dramaturges sous le règne du Roi Soleil.

6 La Postface di A. VIALA, Aperçus sur une archéologie d'un nouveau Parnasse, costituisce la versione scritta delle remarques conclusive del convegno; essa è un vero e proprio manifesto del nuovo Parnasse dramatique. Un indice dei nomi completa il volume. 